University of Massachusetts Amherst

ScholarWorks@UMass Amherst

Communication Department Faculty Publication

Series

Communication

2020

\title{
How white is the global elite? An analysis of race, gender and network structure
}

\author{
Kevin L. Young \\ University of Massachusetts Amherst \\ Seth K. Goldman \\ University of Massachusetts Amherst \\ Brendan O'Connor \\ University of Massachusetts Amherst \\ Tuugi Chuluun \\ Loyola University Maryland
}

Follow this and additional works at: https://scholarworks.umass.edu/communication_faculty_pubs

\section{Recommended Citation}

Young, Kevin L.; Goldman, Seth K.; O'Connor, Brendan; and Chuluun, Tuugi, "How white is the global elite? An analysis of race, gender and network structure" (2020). Global Networks. 124.

https://doi.org/10.1111/glob.12309

This Article is brought to you for free and open access by the Communication at ScholarWorks@UMass Amherst. It has been accepted for inclusion in Communication Department Faculty Publication Series by an authorized administrator of ScholarWorks@UMass Amherst. For more information, please contact scholarworks@library.umass.edu. 


\title{
How White is the Global Elite? ${ }^{1}$
}

\section{An Analysis of Race, Gender and Network Structure}

\author{
Forthcoming in Global Networks [accepted September 2020]
}

Kevin L Young, Department of Economics, University of Massachusetts Amberst

Seth K. Goldman, Department of Communication and Commonwealth Honors College, University of Massachusetts Amberst

Brendan O'Connor, College of Information and Computer Sciences, University of Massachusetts Amberst Tuugi Chuluun, Department of Finance, Loyola University Maryland

\begin{abstract}
Research on elites often utilizes network analysis to describe and analyze the interrelationships among elites and how their prominence varies by demographic characteristics. We examine the diversity of global elites through an analysis of the board members of large corporations, think tanks, international organizations, and transnational policy planning groups. Using new data, we provide the first descriptive picture of global elite networks in terms of race and gender. We also test the 'core-periphery' hypothesis, which predicts that as nonwhites and women achieve elite positions they will be marginalized to the periphery of elite networks, while the core remains significantly more white and male. We find consistent evidence for the core-periphery hypothesis across a range of empirical tests, from simple k-coring to various core-periphery models. Most groups decline in their representation in the core, and this includes white women. White men are the only group that increases in representation in the core compared to the periphery.
\end{abstract}

Knowledge about elites is important in a world of vast inequality, where power and resources are highly centralized among a few individuals. For instance, individuals who serve on the boards of large and consequential organizations make discretionary choices that impact how society is ultimately governed. The composition of elites at a given time thus reflects what kinds of preferences and worldviews will be represented in decision-making. When it comes to elites in official political office, this relationship is widely accepted. Yet the board members of large corporations set corporate policies and oversee the production of goods and services that sustains

\footnotetext{
${ }^{1}$ We gratefully acknowledge the research assistance of Audrey Kearney, Kathrine Esten, Marco Garofalo, Jamil Siddiqui, Trace Dodge, Timothy Scalona, Iza Frachette and Joseph Wenzel. This project is supported by a Research Support Grant by the UMass Amherst College of Social and Behavioral Sciences (CSBS) and an Institute for Diversity Science (IDS) seed grant. We are grateful to Meredith Loken, Eleonora Mattiacci, and Signe Predmore for feedback on this paper. This paper has been presented previously at the Five Colleges International Relations (FCIR) colloquia, Amherst, as well as the Political Networks annual conference, Duke University.
} 
the global economy. The board members of large think tanks and foundations heavily inform which ideas will be investigated, which will be treated seriously by the mainline intelligentsia, which lines of inquiry will be funded, and thus where knowledge will best develop and where it will not. International organizations govern relationships between states, regulate markets, and generate global public policy.

Because board membership is ubiquitous across different types of organizations, these memberships forge ties across organizations, which allows us to examine interrelationships among elites that govern these organizations. Board ties link organizations together through their governing personnel - a board member for General Motors who also sits on the board of the Brookings Institution and the Gates Foundation can act as a mediator between these organizations and transfer information and social cues between them. While the majority of prior work has been focused on the corporate world (Fennema and Heemskerk 2018; Murray 2017), recent research has also investigated connections through a range of different employment ties across organizations (Young et al. 2017; Ellersgaard et al. 2013; Carroll and Sapinsky 2010; Seabrooke and Tsingou 2014). For example, a range of empirical studies find that national elite ties make a difference to strategies of political action (Useem 1984), that Europe-wide ties impact aspects of European governance (Carroll, Fennema, and Heemskerk 2010), and even that transnational board ties of corporations inform political strategies at the national level (Murray 2014; Murray 2017; Chu and Davis 2016; Luther-Davies et al. 2020).

This paper examines the gender and racial diversity of global elites. This is done through an empirical examination of the board members of the organizations that govern much of global resource allocation, power, policymaking, governance, and public discourse: large corporations, prestigious think tanks, international organizations, and transnational policy planning groups. We go beyond extant analyses to study the interrelationships among elites- that is, the dynamics of their social networks, based on ties across board memberships. Prior studies focus almost entirely on simple 'headcounts' of diversity, thus neglecting important questions about how elites are connected to one another through a complex network of board connections. This is important because even if racial and gender minorities achieve leadership positions, they may be marginalized to the periphery of elite networks, giving them substantially less influence in the decision-making process.

Our aim is twofold. First, we provide the first descriptive account of the race and gender composition of the global elite - one that can inform other analyses and prove useful to other researchers and engaged parties. Second, we evaluate the core-periphery hypothesis, which predicts that as non-whites and women achieve elite positions they will be relatively marginalized to the periphery of elite networks, while the core remains more white and more male.

In what follows below we first outline why the composition of global elite networks is important to study empirically. Second, we explain how our study advances current understanding of diversity within global elite networks, how it extends the existing literature, and present our hypotheses. Third, we outline our research methods, which involve constructing a variety of network measures based on the boards of many large and consequential organizations. Our analysis is described in section four, and includes descriptive statistics making use of a variety of core-periphery distinctions within these networks. We find strong and consistent evidence for the core-periphery hypothesis across different forms of measurement: as one moves from the periphery to the core of the global elite network, the proportion of white males increases, while all other groups analyzed decline in their representation. 


\section{Why the Diversity of Global Elite Networks Matters}

Why does the diversity of global elite networks matter? We offer four distinct reasons. First, the background of individuals has the potential to inform their governing behavior. A challenge to this notion might be that organizations themselves, or various 'systemic' pressures, inevitably produce the behavior needed. Yet, several recent high quality studies suggest that the composition of leaders matter, even within organizations facing strong systemic imperatives (Marple 2020; Seabrooke and Henriksen 2017), such as in global policy contexts including how the IMF operates (Seabrooke and Nilsson 2015; Nelson 2014; Chwieroth 2013; Kentikelenis and Seabrooke, 2017), military decisions and foreign policy (Horowitz and Stam 2014; Barceló 2018), nuclear proliferation (Fuhrmann and Horowitz 2014), and democratization (Gift and Krcmaric 2017).

Second, diversity may affect organizational performance. For example, greater gender diversity on corporate boards is associated with positive effects to organizational performance (Sabatier 2015; Soares et al 2015). Racial and gender diversity within corporate management appears to enhance the financial performance of firms (Richard et al. 2013), and a range of effects of diverse management of organizations exist (Wu et al 2019; Li and Chen 2018).

A third reason why the composition of elites matters is because the diversity of global elites affects issues of representation and legitimacy of large and powerful organizations. The representation of different race or ethnic groups within national political systems is a contentious political issue in many societies, in particular when these factors cluster around wealth and income. Racial representation within the U.S. court system, for example, affects perceptions of its legitimacy, albeit in complex ways (see Scherer and Curry 2010); within universities (see Thomas 2020; Warikoo 2016), racial representation is a major issue leading to a variety of institutional changes. Concerns of representation are particularly salient for organizations that operate with global reach. If an international organization has a mandate to secure some public good for literally the entire human population and yet has an executive leadership that is racially homogenous, modern values of representativeness may mean the weakening of this organization's legitimacy. Within international organizations, legitimacy is a major theme and ongoing dilemma (Dietz et al 2019; Bexell 2014). Who is represented on the governing bodies of international organizations, for instance, is often seen as one of the most crucial metrics for assessing its ability to carry out fundamentally 'global' public policy functions (see Zuern 2018; Hale et al 2013; Held and Young 2013). As such, there are now widespread movements under way to address gender and racial diversity within large and consequential organizations, in particular in the corporate world but not confined to it, across the globe (see Alliance for Board Diversity and Deloitte 2019; Alliance for Board Diversity 2013).

Fourth, knowledge about how global elites operate as a social network is valuable in the context of ongoing economic globalization and the changing distribution of wealth it has brought. If the composition of the executive leadership of large and consequential organizations is important, then the social dynamics of elites are by necessity consequential. The operating assumption of the study of elite networks is that elites interact with one another not just within organizations but across many organizations. These multiple ties are consequential, not just because they exist but because they are variable and unequal - a major analytical point reinforced by elite network analysis since its inception (Fennema and Heemskerk 2018). 
A key question within the study of elite networks is how these forms of interaction adapt to change, and in particular how the balance of behaviors reflecting in-group solidarity with norms of inclusion operate. Within the United States, for example, major studies of elite networks emphasize the importance not just of being male and of being white, but of being Protestant (Baltzell 1966; Baltzell 1984). Yet groups that were systematically excluded made their way into elite circles through various professional and social movement struggles over time. The incumbent group in the U.S. - white, Protestant males - adapted to social change and pressure through selective inclusion of some marginalized groups, albeit in different and partial ways. Importantly, different groups that were previously excluded have had radically different trajectories - as emphasized by studies of women (Zweigenhaft and Domhoff 2006), Blacks (Zweigenhaft and Domhoff 1991) and Jews (Zweigenhaft 1982).

Over the last several decades, the center of global elite networks has been more or less stably oriented around one region of the world: the North Atlantic. This has meant that the privileged social group of the North Atlantic - that is, white, educated males who speak fluent English - has had enormous advantages. The accelerated rise of Japan in the 1970s and 1980s made inclusion of Japanese corporate elites a paramount concern for elites of the North Atlantic and groups such as the Trilateral Commission (Luna and Valasco 2017; Sklar 1980) were established to include Japanese leaders into the ambit of the North Atlantic elite network.

While globally the center of elite networks is oriented around the North Atlantic, the planet's economic center of gravity is returning to its long-run equilibria in the East (Wile 2012; Quah 2011). While this is associated with phenomena such as the re-emergence of Chinese economic prominence, and South and East Asian economic prominence generally, there are several indications that such a transformation informs elite sociality. According to the World Inequality Database, the proportion of super-rich - the $0.001 \%$ of the global population - have gotten unambiguously more Chinese, more Indian, and less European than in the past. In the largest study of transnational corporate interlocks to date, Heemskerk and Takes (2016) find evidence for a separate 'East Asian' cluster within the global network. De Graaf and Van Appeldoorn's (2018, 2017) analysis suggests that the Sino-Chinese relationship, and its mediation through elite networks, is not just becoming a major issue in international politics because China is important, but also because of differential integration of elites into global networks of power.

There are of course important demographic shifts occurring within national societies as well, to say nothing of the way that greater gender and racial diversity efforts have been a part of ongoing social movement activity. Both demographic shifts and social movement efforts to change norms and policies around inclusion and diversity have been prominent within the North Atlantic in particular and their impact has deeply informed contemporary politics, both in terms of progress toward racial and gender diversity, and in terms of populist (counter)reactions to this diversity and its perceived effects. Yet there is very little that we know about the state of diversity among the global elite, although there is some interesting progress on the study of elite demographics in general, as we describe below.

\section{Approaches to Studying Diversity Among Elites}

While dynamics of racial and gender discrimination within society at large are now heavily studied terrain, the study of these dynamics among powerful people like elites is very rare. Within the contemporary study of elites, there is a dearth of understanding regarding how social dynamics such as race and gender norms of inclusion and exclusion operate. Prior research has focused 
primarily on measuring changing diversity within the so-called 'power elite,' in particular on the leaders of large U.S. corporations (Zweigenhaft and Domhoff 2006, 2011, 2018). Other analyses have examined the inclusion, over time, of particular minority groups. These include longitudinal studies of minority groups such as Jews (Zweigenhaft 1982), Blacks (Zweigenhaft and Domhoff 2003), and women (Bernile, Bhagwat, and Yonker 2018) within the boards and CEO-suite of the U.S. corporate world. These studies, and others like them (Deloitte 2017; Catalyst 2016; Hagendorff and Keasey 2012; Martin and Herrero 2018; Mayer, Warr and Zhao 2018; Domhoff and 2011), share three primary limitations. First, they measure diversity only with counts of the total number of minority group members in organizational leadership positions. Second, the organizations they examine are - almost without exception - corporations. And third, these studies are U.S.-centric, and thus largely neglect organizations in the rest of the world.

Our project significantly extends prior analyses in several ways, beginning with analyses that go beyond just the corporate world and into a broader organizational terrain, in acknowledgement of the array of organizations that reflect elite sociality (Khan 2012; Young et al. 2017; Carroll and Sapinsky 2010). In addition to examining the top corporations in the world, we study a range of organizations, including think tanks, international organizations, non-governmental organizations, and transnational policy planning groups.

Race and gender have been analyzed among elites, though only in a few exemplary studies. In particular, Domhoff and Zweigenhaft's studies $(2011,2016)$ have examined multiple dimensions of expanded and differentiated elite inclusion, and provide the building blocks for analysis of the kind we are conducting here. Yet we are aware of only one existing study that has ventured into the terrain of assessing diversity within the global elite. This is the work by Zieliński (2017), which analyzed the race and gender composition of the Trilateral Commission over time. The Trilateral Commission is a very important transnational policy planning group, and we include it in our analysis. However, it is also only one of ten transnational policy planning groups that have been part of broader studies (Carroll and Sapinski 2010). An advantage of Zieliński's study is that it utilizes Trilateral Commission conference attendance over time. While Zieliński (2017) only offers simple counts and a few paragraphs, they do find that women and non-whites are generally excluded from the inner circle of the Trilateral Commission, which is defined as those that have attended at least 16 conferences.

We use network analysis because it allows us to establish how emergent social structures develop out of complex relationships between elites. The notion of an elite 'core' or, as it is sometimes known, an 'inner circle' (Useem 1984) is a keystone concept within the study of elite networks (Larsen and Ellersgaard 2018), and one we make use of in this context. The core or inner circle is essentially the group of individuals who not only have superordinate control over resources at their command (all elites generally qualify for this) but who also occupy an especially prominent place within elite social networks. The inner circle is believed to help maintain the class identity of the elite. Serving on multiple corporate boards meant that the interests of one's business operations as a manager of particular capital - e.g. Walmart - was moderated by the interest of capital in general (Scott 1985). It also served to moderate (Useem 1984; Mizruchi 2013) corporations' political roles, since the inner circle participants held moderate and pragmatic political views close to the average preferences of the network, and thus protected the status-quo. Individuals within the inner circle are much more likely to coordinate their political activities than those within the periphery - a finding that has shown to be robust historically in qualitative studies, in longitudinal studies, and at both the national and global levels of elite sociality (Murray 2014; Mizruchi 2013; Chu and Davis 2016). 
Using the inner circle concept, core-periphery distinctions are made empirically to distinguish, usually qualitatively, those with inner circle status (the core elites) from those without (the peripheral elites). This has been done in many prior studies, including those of global elites (Carroll and Sapinsky 2010; Murray 2017). Numerous studies have used core-periphery distinctions to study corporate interlock ties in specific countries as well. For example, recently Comet (2017) examined the core-periphery structure of the policy-planning network in France; Naudet and Dubost (2017) do the same for Indian corporate ties; Chu and Davis (2016) examine the evolving disappearance of the inner circle in the United States, and Larsen and Ellersgaard (2017) examine the inner circle of the Danish elite.

We assess how proportionately representative different race and gender groups are within the global elite. We expect white males to be the most well-represented 'incumbent population' within global elite circles. Theoretically, mechanisms of in-group solidarity might be strongest within the 'core' of the network, where incumbent white male leaders have enjoyed a position of historic dominance. Establishing the 'core' of a network distinct from the 'periphery' is extremely useful because it conforms to notions of social exclusion and insider-ism that pervade social life. On the basis of mechanisms of race-based social exclusion (Royster 2003; Althauser et al 1975), one can easily imagine that, for example, predominantly white male social networks marginalize blacks (Zweigenhft 2003) or treat East Asian females differently. At the same time, there may be incentives for 'tokenism' within corporate boards, other strategic considerations (Heemskerk and Fennema 2014), or changing norms within elite strata that countervail a white male incumbency advantage, and we acknowledge that the dynamics of race and employment are not straightforward (Fernandez and Fernandez-Mateo 2006).

While it is plausible that the demographic and geopolitical shifts mentioned above will change the shape of elite networks, it is also possible that the inner circle of elites will not change in the face of these shifts. Indeed, resilience of corporate networks has been found in previous research in the face of dramatic changes to corporate structure. Davis, Yoo and Baker (2003) examine the relationship between elite network structure and corporate governance change over time (looking at 1982, 1990 and 1999 in the U.S. specifically), and find that the structure of the U.S. corporate elite has been resilient to changes affecting corporate governance.

We acknowledge that corporate organization, and thus the network properties of the corporate elite, varies significantly across countries (Scott 1991). There exists a range of literature on corporate networks outside of Europe and North America, such as work by De Graaf $(2019,2014)$ on Chinese elites, Cardenas (2016) which compares elite networks across Latin America, and Murray's (2006) work on elite networks in New Zealand and Australia. Schoettli and Pohlmann (2017) provide an analysis of economic elites in India and their integration within transnational networks. Studies confined to the North Atlantic found that these corporate board networks share some similar properties ${ }^{2}$

\footnotetext{
${ }^{2}$ For example, Conyon and Muldoon (2006) examine the properties of corporate board networks in the US, Germany and the United Kingdom. They compare a variety of network properties to random networks and find these board interlock networks to be not substantially different from random networks when it comes to how 'clubby' these networks are. They do however find positive degree correlation among corporate board members, meaning that board members on multiple boards tend to be connected to those with others who also sit on many boards.
} 


\section{Constructing a Global Elite Network}

To study global elite networks we need a collection of people to study. To establish this population, we follow extant research in this area that suggests we can start with a collection of globally powerful organizations to arrive at such a population. While corporate boards are the primary way in which global elite networks have been studied, the majority of theorizing about how elite power reproduces itself suggests a range of large and consequential organizations, through which individuals of exceptionally high social standing circulated (e.g. Mills 1956; Bourdieu 1996). Seabrooke and Henriksen (2020, this issue) note that elites in transnational policy networks are those that have disproportionate influence over policy design and implementation on issues of global importance. This includes an array of occupational positions, but surely includes the board members of large and consequential organizations beyond just corporations. Existing scholarship has sometimes examined the interface of corporate boards and selected policy planning organizations (Carroll and Sapinski 2010; Carroll and Carson 2003; Sapinsky 2015).

For our sample, we go further to include a wider array of organizations that are involved in governance, that control resources, and that are globally prominent. Because there is no clearly established population of organizations, we select an informed group that we describe below: large corporations, think tanks, international organizations, transnational policy planning groups, and non-governmental organizations. Our approach self-consciously departs from a Bourdieusian approach in which elites are defined in field-specific ways.

Large corporations are undoubtedly consequential organizations and so are included. We select a top list of global corporations in the following way. Ranks in terms of total revenue, rather than assets, is sometime preferred, because ranking by total assets yields mostly large financial institutions. Thus, an approach we will adopt, following precedent in other studies (Carroll and Sapinsky 2010; Stokman et al. 1985), is to have two thirds non-financial firms ranked by revenue and then the largest financial firms ranked by assets. We include 30 corporations -20 non-financial and 10 financial. A larger sample of corporations is of course possible, and we acknowledge that most purely corporate board interlock studies have a larger sample of corporations. Yet any cut-off is inherently arbitrary, and this study includes an array of different organizations beyond corporations. Given a known distribution of corporation size in the global economy by assets or revenue (Young 2015), the 30 corporations included are likely fairly representative.

Our study includes globally influential think tanks due to the prominent role they play in the formation of ideas and policymaking (Salas-Porras and Murray 2017; Rich 2004). Moreover, their outputs - in the form of research and advocacy strategies - are used by other powerful organizations and individuals. Think tanks produce, nurture, and promote public intellectuals (Misztal 2012); they contribute to policy advisory systems (Fraussen and Halpin 2017); their activities frequently have global influence on social and economic policy (Dabrowski 2014; McGann, Viden and Rafferty 2014; Shoup 2015), and the work of think tanks often brings together corporate and government officials (McGann 2016; Garsten 2014), often across transnational networks (Struyk 2002). We selected the most prestigious 30 think tanks in the world, using the 'Global Go To Think Tank Index' (McGann 2018). ${ }^{3}$

\footnotetext{
${ }^{3}$ This is a league table produced by the Think Tanks and Civil Societies Program (TTCSP) of the Lauder Institute at the University of Pennsylvania. ${ }^{3}$ This is a widely used index that has been vetted in several stages to ensure rigor. In a first stage, a call for nominations is sent to approximately 6,500 think tanks and 7,500 journalists, public and private donors, and policy makers from around the world. Those organizations that
} 
An influential yet often overlooked set of organizations that we include are transnational policy planning groups, such as the International Chamber of Commerce, the World Economic Forum, the Trilateral Commission, and other organizations that operate as coordination hubs for business, government, and think-tank organizations. These policy planning groups have played an important role in formulating policies for global governance (Zieliński 2017; Carroll and Sapinsky 2010; Carroll and Carson 2003). The Trilateral Commission, for example, has brought together government leaders, business executives, and leaders of prominent think tanks since the 1970s to guide policy agendas around the world (Luna and Valasco 2017; Sklar 1980). Several prior studies attempt to utilize the membership data of just one of these organizations. In Zieliński (2017) the focus is on the Trilateral Commission; in Luther-Davies et al. (2020) the Council of Foreign Relations is used as the key indicator of U.S. elites' connection to the policy planning network. We include the boards of the 10 most prominent transnational policy-planning boards with global

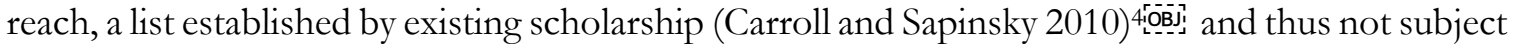
to our own discretionary choice, in terms of number of organizations.

To represent public organizational groups at the international level, we include the governing boards of 6 major international organizations that represent the major public-sector entities operating under the guise of global governance. ${ }^{5}$ These are different than transnational policy planning groups, which are essentially private club organizations. We also include a variety of non-governmental organizations (NGOs), specifically the top 10 that were globally ranked in 2015 (the closest date we could obtain to the present at the time of our data collection) ${ }^{6}$ ions]

The boards of all these organizations were collected for the year 2018. We found lists of board members through annual reports of organizations, and we found extended connections of these

obtain 10 or more nominations are then placed in an electronic ranking survey, with a final list generated through this process and finally adjudicated by an expert panel to make final selections.

${ }^{4}$ These include the International Chamber of Commerce, the Bilderberg Conference, the Trilateral Commission, the Council on Foreign Relations, the World Business Council on Sustainable Development, the UN Global Compact, the European Round Table of Industrialists, the EU-Japan Business Round Table, TransAtlantic Business Dialogue. We also include, contra Carroll and Sapinsky (2010), the Group of 30, an important private club composed of public officials and private sector individuals developing agendas for international economic affairs (Tsingou 2015). The North American Competitiveness Council, which Carroll and Sapinsky (2010) also use, is no longer in operation. The Council on Foreign Relations is defined as a think tank for our study and is thus not included in this group.

${ }^{5}$ Specifically, we include the Executive Directors of the International Monetary Fund (IMF), the Executive Directors of the World Bank (specifically the IBRD), the Chair and Bureau of the Committee of Permanent Representatives of the UN Environment Program (UNEP), the senior representatives of the UN Security Council, and the governing Executive Committee of the UN High Commission on Refugees. We also include the UN 'Chief Executives Board for Coordination', which is composed of the Executive Heads of the UN, it's 12 Funds and Programs, the 15 Specialized Agencies of the UN, it's 3 'Related Organizations', and is chaired by the UN Secretary-General.

${ }^{6}$ These include Medicines San Frontieres, BRAC, Danish Refugee Council, the Grameen Foundation, ACUMEN Fund, Oxfam, Partners in Health, Islamic Relief International, Save the Children, and World Vision. This top list was constructed by a global study of NGOs, called NGO Advisor (formerly GlobalGeneva), which has maintained a distinct methodology for ranking global NGOs, developed by Jean-Christophe Nothias, former editor in chief of The Global Journal. An NGO was defined as "operational or advocacy-focused nonprofit organizations" that focus on the public interest and are nonprofit organizations. Nothias began a ranking methodology in 2009, which underwent a commissioned academic review in 2013 (Cannon 2013) and is also subject to critique within the NGO community itself (in the same way that university rankings are contentious, for example). The ranking process involves a public codebook, and involves a survey of over $2000 \mathrm{NGOs}$ worldwide, excludes business interest NGOs (such as business associations). 
individuals through their websites, web searches, and other information aggregators such as Bloomberg, Wikipedia, and Capital IQ. The organizations are a 'top slice,' not a probabilistic sample, so they represent an informed, curated sample of the largest and most prestigious organizations, with an over-representation of global corporations due to their centrality in global elite networks. The list constitutes 96 different organizations, of varying sizes, capacities and remits. One potential critique is that we overrepresent organizations based in certain regions of the world. However, the fact is that the most powerful organizations in the world are headquartered in a limited number of regions: the U.S., Western Europe, Japan, and increasingly, China. ${ }^{7}$ This is an important and concerning finding in itself. The majority of the organizations nonetheless have a global remit and are not focused on any particular country or region. For example, Amnesty International is headquartered in the U.K., the World Business Council on Sustainable Development in Switzerland, and BRAC in Bangladesh, but all have offices across the world and all deal with fundamentally 'global' issues that stretch far beyond their headquartered countries.

We are conscious that our sample population is drawn from the governance of organizations that is, 'organizational leaders'. Consequently, other categories of elite status - such as extreme wealth or other forms of prestige and social connection - may be absent from this sample, inasmuch as some individuals with these characteristics do not govern the boards of organizations. Yet our study should also be seen in the context of the vast majority of exercises to examine transnational class formation or global elite networks that focus, usually exclusively, on corporate board members and/or CEOs only. Our inclusion of a range of large and consequential organizations, that constitute an array of governance practices, represent a far more encompassing sample than those included in past studies.

\section{Analysis}

From the population of board members of organizations described above, we generated a list of approximately 1600 individuals governing these 96 organizations circa 2018. We first build a network composed of all the board members of only the organizations described above, which we call the 'base' organizational network. Although the 'base' organizational network provides a more complete depiction of the board ties in our original sample, it likely underrepresents the array of actual ties that elites have to one another. We then searched for the ties of these individuals outside the organizations originally sampled. ${ }^{8}$

We conducted a variety of quality control checks following the best practice standards (Heemskerk et al. 2018). In particular, we conducted checks on entity resolution (Marple et al. 2018) using sorted lists of organizations and names, and looking up organizations when names were ambiguous. While we are confident that we searched thoroughly for all available board ties for these individuals, and we performed several reliability checks along the way, there is likely some

\footnotetext{
${ }^{7}$ Relatedly, we note that several studies of corporate elites within Europe and within Latin America have found a lack of evidence of significant transnational ties relative to national ones (Vion et al. 2015; Cardenas 2014).

${ }^{8}$ The extended organizational network is different because it contains all of the board memberships of the base organizational network but, in addition, also contains an expanded list of other connections of each individual in our population. Thus, while for example while 'John Smith' may be on the board of the World Economic Forum (which is part of our 'base' group of organizations) we also found that he was on the board of Harvard University, Exxon Mobil, and the Japanese Association of Manufacturers. While the latter three organizations were not on our base-organization list, they are relevant for establishing connections between elites, and they may prove to be direct ties or part of connected pathways between elites.
} 
degree of error nonetheless. It is also inevitable that some ties to non-base organizations exist but were not found.

Table 1 summarizes these networks. Nodes include the individuals and organizations in the 2mode network, while an edge connects an individual to an organization. Table 1 suggests a tradeoff: the Base Organizational Network is more complete, while the Extended Organizational Network is more representative of the larger population. We include a number of simple network level statistics of each network for comparison and because they may be useful to other researchers composing other elite networks, either at the global or national level.

\begin{tabular}{|c|c|c|}
\hline \multicolumn{3}{|c|}{ Table 1} \\
\hline & $\begin{array}{c}\text { Base } \\
\text { Organizational } \\
\text { Network. }\end{array}$ & $\begin{array}{l}\text { Extended } \\
\text { Organizational } \\
\text { Network }\end{array}$ \\
\hline Number of individuals & 1590 & 1590 \\
\hline Number of nodes & 1683 & 6735 \\
\hline Number of edges & 1650 & 9176 \\
\hline Density & 0.017 & 0.039 \\
\hline Average Path Length & 3.430 & 2.640 \\
\hline Modularity & 0.917 & 0.514 \\
\hline Transitivity & 0.931 & 0.601 \\
\hline
\end{tabular}

Race was coded using standardized headshot pictures collected for each individual in the sample. Coding race is complicated first by the fact that perceptions of an individual's race vary by the surrounding contexts (Simon and Piche 2012; Roth 2016). Second, racial categories are subjective. There is no underlying property conforming to what most people mean by race, especially across different national and regional contexts (Roth 2017). Existing scholarship that has coded the race of U.S. elites defines race in fewer categories than we employ, for example treating both South Asian and East Asian individuals under the category 'Asian' (Zweigenhaft and Riplinger 2011). Other scholarship outside of the U.S. has used categories that may be appropriate for a given local context but not globally. For example, Murray (2001) used 'Anglo South African', Black, Afrikaans, Jewish, and Indian as their categories for the board members of South African organizations. After examining a variety of racial categorization methods used in different parts of the world, we opted for the most generalizable categories that could be reliably coded. Table 2 below lists the racial categories as well as their percentages in the sample of organizational leaders. We ran inter-coder reliability checks on the classification of our sample population, using a random sample of the standardized headshots of 400 individuals, and found inter-coder reliability to be high, using both Cohen's (1960) kappa score and Gwet's (2008) AC coefficient.?

\footnotetext{
${ }_{9}$ Specifically, with 6 categories and 2 coders, raw agreement was $86.5 \%$, while Cohen's unweighted kappa score was $75 \%$, and Gwet's AC value was $84.5 \%$. The highest level of raw disagreement was between White and Hispanic categories. Revising to just 5 categories across the two coders yielded raw agreement of $95 \%$, with Cohen's kappa value of $89.2 \%$ and Gwet's AC at $94.3 \%$. Both of these analyses suggest that agreement was stable across coders, but we recognize that perceptions of race categorization are themselves contested (Brown et al 1998; Roth 2017), and have explored this variance in a separate project.
} 
Table 2

\begin{tabular}{lrcc} 
Race Category & \% Sample & $\begin{array}{c}\text { \% of which } \\
\text { Men }\end{array}$ & $\begin{array}{c}\text { \% of which } \\
\text { Women }\end{array}$ \\
\hline Black & 6.6 & 62.9 & 37.1 \\
East Asian & 11.3 & 85.5 & 14.5 \\
Hispanic & 2.3 & 81.1 & 18.9 \\
Middle Eastern & 2.3 & 73.7 & 26.3 \\
South Asian & 4.3 & 76.8 & 23.2 \\
White & 73.1 & 74.6 & 25.4
\end{tabular}

\begin{tabular}{lll} 
Race & Gender & $\begin{array}{l}\text { \% of Total } \\
\text { Sample }\end{array}$ \\
\hline Black & Women & $2.45 \%$ \\
Black & Men & $4.15 \%$ \\
East Asian & Women & $1.64 \%$ \\
East Asian & Men & $9.63 \%$ \\
Hispanic & Women & $0.44 \%$ \\
Hispanic & Men & $1.89 \%$ \\
Middle Eastern & Women & $0.63 \%$ \\
Middle Eastern & Men & $1.76 \%$ \\
South Asian & Women & $1.01 \%$ \\
South Asian & Men & $3.34 \%$ \\
White & Women & $18.57 \%$ \\
White & Men & $54.5 \%$
\end{tabular}

Gender is not a simple binary variable, and is also a multifaceted social construct. Because we do not know an individual's own gender identity, we chose to classify binary gender based on our perceptions of each elite's gender through their headshots. Although we cannot know how well our perceptions coincide with the individuals' self-identification, it is outsider perceptions that most likely inform treatment of those individuals in their professional life. Employing a binary gender categorization is also imperfect given the multitude of gender identities to which people adhere. Unfortunately, the challenge of coding transgender and non-binary identities is beyond the scope of this study. Our sample is overwhelmingly male and white: males are $75.3 \%$ of the sample and whites are $73.1 \%$ of the sample.

While these initial descriptive findings are interesting, our primary focus is how race and gender are related to the structure of elite networks. In what follows, we first conduct a k-coring exercise to examine how the representation of different groups changes across the network. We then deploy a variety of core-periphery models on the network to assess whether and how different groups are represented on the core compared to the periphery.

\section{Step 1: K-Coring in 2-Mode Network}

We first analyze how race and gender representation changes among more highly-connected parts of the network at different levels of k-core decomposition. A k-core of a network is composed of 
all of the nodes that continue to be included in a network, when only those with at least $\mathrm{k}$ connections are included (Seidman 1983; Batageli and Zavernik 2002). It is the 'sub-graph' where all nodes have a degree of at least k. For example, to construct the 4-core of a network, one first eliminates all nodes with 3 or fewer connections; this in turn leaves some nodes with fewer than 4 connections, so the process is iterated until those that remain have at least 4 connections each. For our 2-mode network of individuals and organizations, the resulting 4-core would include the maximal set of individuals who are on the boards of 4 or more organizations in the 4-core, which in turn have at least 4 board members within this set. This structural characteristic of a k-core represents a highly interconnected elite set of individuals and organizations. We focus on the individuals in each $\mathrm{k}$-core from $\mathrm{k}=1$ (the original network of 1590 individuals) to the highest $\mathrm{k}$ the network will decompose to. For the base organizational network, the maximum k-core is 2 , which contains 43 highly interconnected individuals, and for the extended organizational network the maximum is a 4-core, which is comprised of 151 individuals.

Figure 1

Race and Gender Representation by K-Core Decomposition

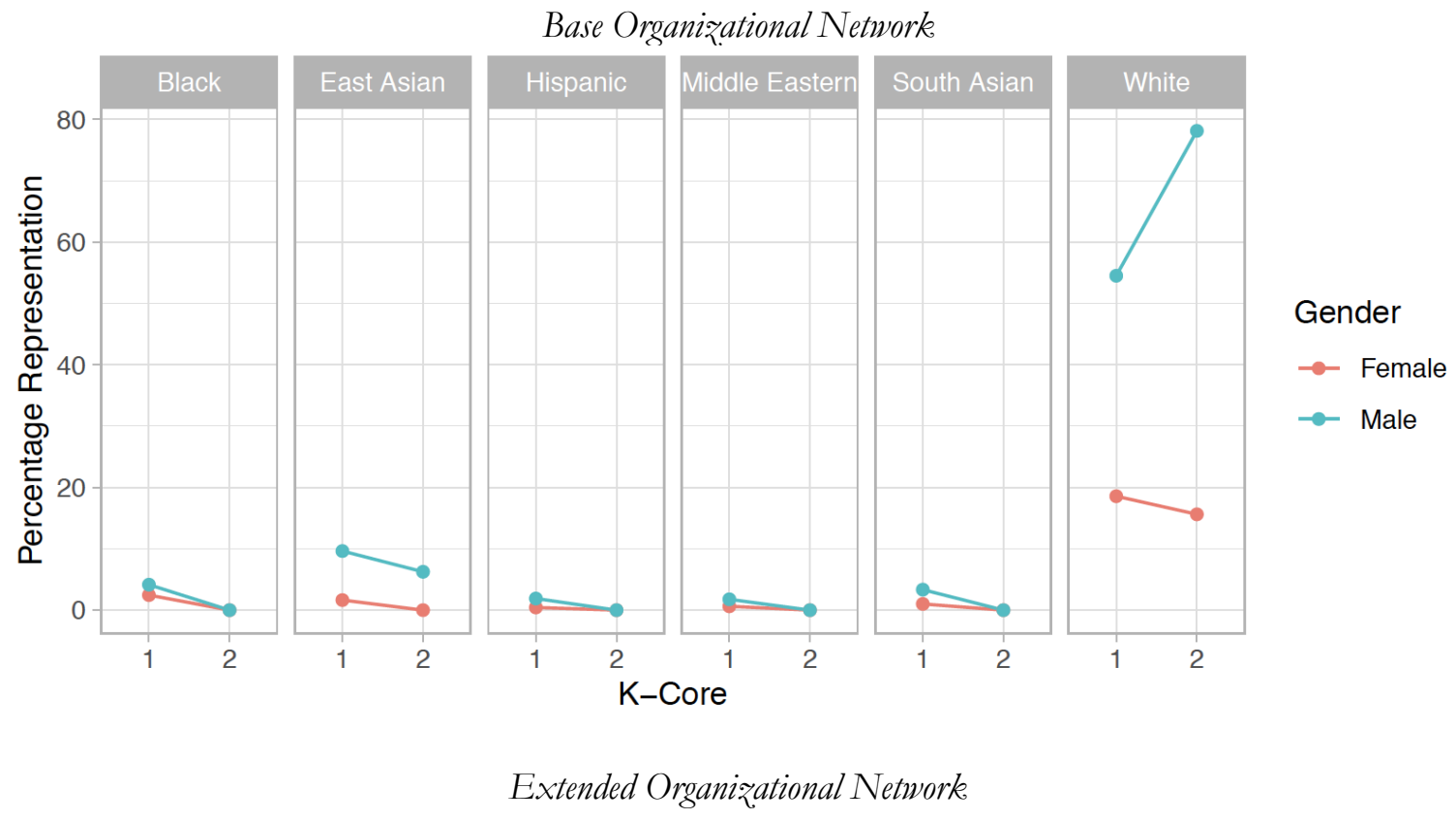




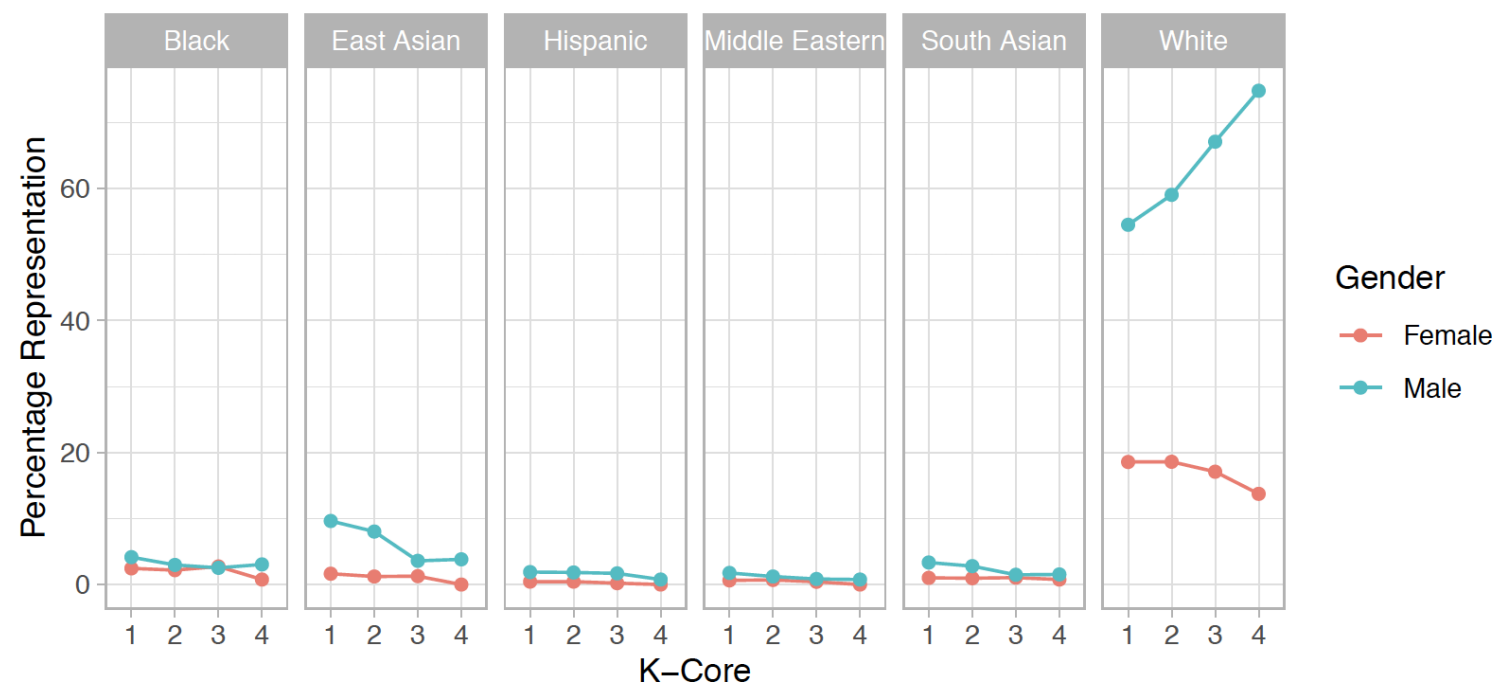

As the network is 'k-cored', we assess how the representation of different groups changes. Our findings suggest that white males are not only the dominant group in the network, but that their representation increases as the k-core increases. In the base organizational network, their representation increases from $57 \%$ in the 1 -core to $72 \%$ in the 2 -core network. In the extended organizational network, white males increase from $60 \%$ in the 1 -core network to $70 \%$ in the 4 core network. In other words, as we move from the periphery toward the more densely interconnected 'core', the network becomes even more strongly dominated by white men. White women are the second highest represented group in the extended organizational network at $18.57 \%$ of the total, but their representation notably declines as the k-core increases, down to $13.74 \%$ in the 4-core. These differences between white men and women suggest that it is not race alone that drives the social organization of the network, but a combination of race (whiteness) and gender (maleness).

The situation for non-white categories of elites is more complex. Within the base-organizational network, the presence of all such individuals, whether male or female, decreases as the k-core increases. For the extended organizational network, this is still true from the 1-core to the 4-core, although there is some marginal increases in representation from the 3-core to the 4-core, in the case of Black men and East Asian men, for example. Herein the small number of individuals in some categories raises a double-edge sword. On the one hand, smaller numbers mean a lower confidence in observed variance. Yet on the other hand, the small number of individuals is itself indicative of the state of diversity among global elites. For example, while there are 69 South Asians in the network as a whole, there are only 3 in the 4-core network - and only one of them is a woman. While there are more Black individuals in the network, at 105, in the 4-core network there remain only 4 , again with only 1 woman.

This initial examination of our elite network, using simple k-coring methods, supports the coreperiphery hypothesis. Next, we turn to a more stringent series of tests for differentiating the periphery from the core to evaluate the robustness of these findings.

\section{Step 2: Core-Periphery Models in 1-Mode Network}


A range of core measures aside from k-coring are available, but most are intended to be used with a 1-mode network, consisting only of interconnected individuals. Figure 2 illustrates our base and extended networks as 2-mode networks (first row) of individuals and organizations, and as 1-mode networks (second row) composed only of individuals. Organizations are shown in green and disappear in the 1-mode network where we remove edge color because of the greater density of ties to facilitate visualization.

Projecting our 2-mode network (individuals and organizations) onto a 1-mode network (only individuals) entails a transformation of node-level attributes that count ties, since board size is not uniform across organizations. ${ }^{10}$ Collapsing a two-mode network to a one-mode network poses the risk of representing individuals on large boards as more highly connected than individuals on small boards, regardless of their degree of connectivity across organizations (Carroll and Sapinsky 2010). For this reason, we focus on core-periphery distinctions, which relate to differential prominence among sub-components of the network as a whole. ${ }^{11}$

To address the issue of differential board size in the 1-mode network, we use a weighting method whereby multiple ties between individuals across organizations are worth more than a single tie between individuals within an organization. For example, two individuals that have common ties across four organizations have a weight of 4, while two individuals with ties within one organization (i.e. they are on the same board) have a weight of 1 . In the instances where such edge weights are incorporated into a minimal distance path across the network, we invert this measure so that the stronger ties between individuals represent 'less path' to travel, while the weaker ties between individuals represent 'more path'.

Figure 2

Visualizations of Elite Network, by Mode and Type

2-Mode Base Organizational Network

2-Mode Extended Organizational Network

\footnotetext{
${ }^{10}$ While corporate boards vary in size, this is not usually by a great deal. For example, Berkshire Hathaway and Acumen have boards of 14, while JP Morgan and Barclays have boards of 15. Other types of organizations have either larger or smaller boards. The Council on Foreign Relations, however, has a board of 37 people, and the EU-Japan Business Roundtable has a board of 48 people, and UNESCO has a 6-person board.

11 Weighting ties to normalize to the size of boards is another possibility, but it is fraught for two reasons. First, it entails strong assumptions about how less connected individuals are in a larger board versus a smaller one. We simply have no way of knowing, although future research may hold some promise on this property. Second, weighting to normalize to the size of boards is only possible in the base-organizational network setting, since the extended organizations are not necessarily composed of all board members, even though the base-organizations are, due to our method of data collection. For example, if Northrup Grumman is not on our base-organizational list, but 10 people are connected to it, it would appear that Northrup Grumman has a board of 10 individuals, which may be correct or incorrect but entails verification of actual board size in order to be accurate.
} 


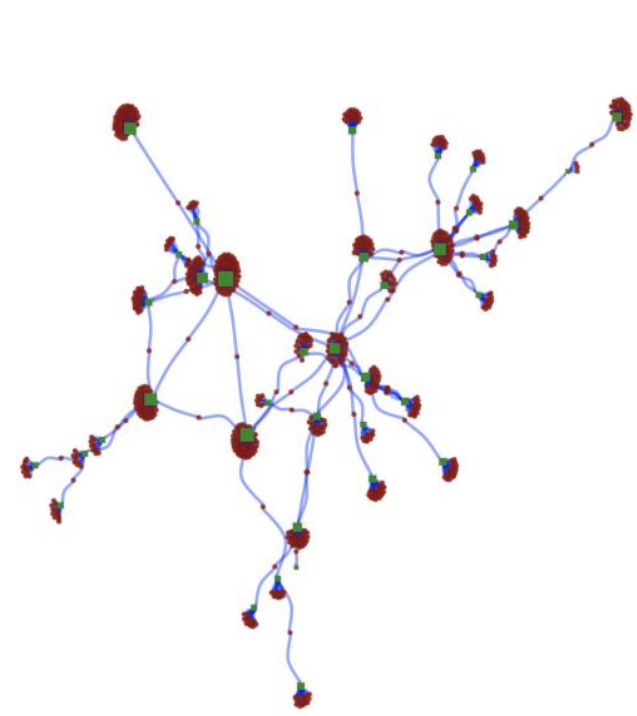

1-Mode Base Organizational Network

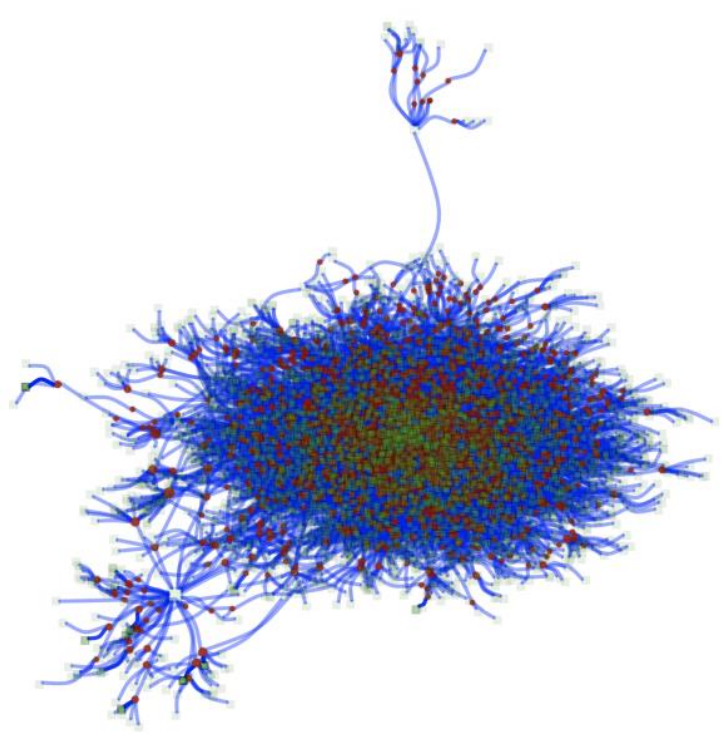

1-Mode Extended Organizational Network
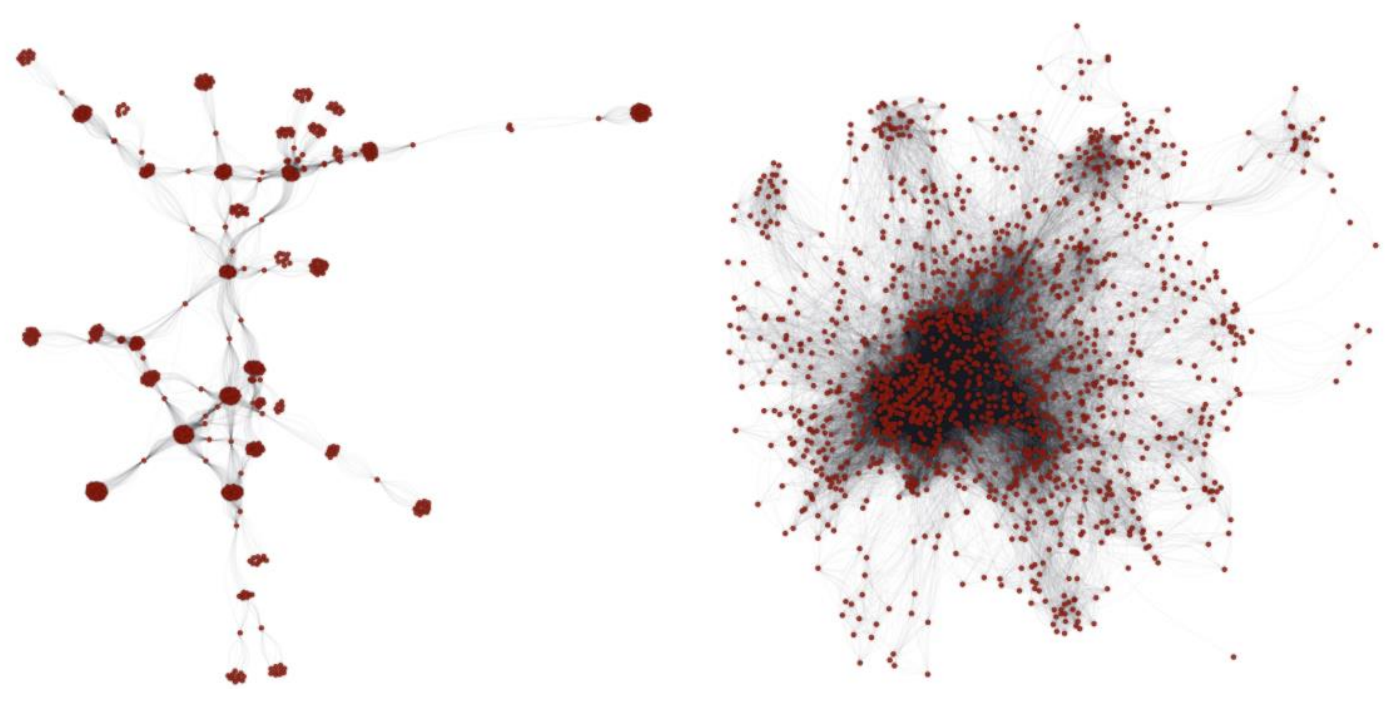

A core-periphery structure in a network means that there are a set of core nodes which are densely interconnected, in contrast to peripheral nodes, which are more loosely interconnected. Our method of analysis with the 1-mode network is to assess whether the relative representation of different race and gender groups is different in the 'core' of the network compared to the periphery. If the core, for example, is more proportionally represented by whites than by nonwhites, then this would support our core-periphery hypothesis. Different methods are available for ascertaining a core-periphery structure of a network, and new innovations have been recently proposed (Cinelli et al 2017; Rombach et al 2017; Kojaku and Masuda 2018). We use three of these new measures to assess the consistency of our findings across methods. While we cannot adjudicate between these methods, a consistent finding that appears across methods would further suggest that is the patterns observed in the data are substantively present in the broader population of global elites. 
The first is the 'rich-core' method developed by Ma and Mondragon (2015), which identifies the nodes in the hub of the network that play a dominating role in structural and functional properties. This method makes use of edge weights and thus is attractive because it incorporates the greater intensity of connection among some elites within organizations. The $\mathrm{Ma}$ and Mondragon algorithm is easily scalable to relatively large networks such as ours, and does not entail choices about parameters, with the exception of the edge weights that we incorporate. It has been used to analyze the core within the global trade network (Ma and Mondragon 2015), but we are not aware of it being applied to the study of elites.

Second, we use the method of 'network back-boning', which is a process to filter non-significant edges from a very dense and noisy network such as ours. Back-boning preserves the edges that represent statistically significant deviations with respect to a null model for the local assignment of weights to edges (Serranno et al. 2009). It has been applied to the analysis of U.S. airport networks as well as natural systems such as food webs (Serranno et al. 2009). Like the other methods we deploy, it also incorporates the information from weighted edges to ascertain the backbone of the network. The only parameter for the 'disparity filter' algorithm it uses is the statistical significance level at which the model analyzes the data, which we set at the conventional $5 \%$ p-value. ${ }^{12}$

Third, we use the coring method developed to analyze elite networks by Larsen and Ellersgaard (2017), which has been used to study the Danish elite. Their 'eliter' method produces a score of 'coreness' for all individuals in the network. This method has more discretionary steps than other methods but conforms extremely well to notions of an 'inner circle' within the study of elites. While some scholarship takes simpler measures of an inner circle on the basis of multiple ties ( Heerwig and Murray 2018; Murray 2017), Larsen and Ellersgaard utilize the structural properties of the network. A minimal distance path is computed between all individuals in the network, ${ }^{13}$ then a score is attributed to those individuals who are able to 'reach' other individuals more efficiently than others. Because of the nature of this method, we used inverted edge weights, such that two individuals with multiple ties are defined as more easily 'reachable', while two individuals with a single tie are 'less reachable'. Those that can reach one another very efficiently, based on the distance traveled along network paths, have a higher coreness score. ${ }^{14}$ This method produces a continuous measure of coreness, and defines the inner circle as those with the maximum coreness score. For our purposes, we take the $90^{\text {th }}$ percentile of coreness scores to define the inner circle, although our results are similar when we use the maximum coreness scores.

Figure 3 shows a series of results, using the extended network data, analyzed via the three different core-periphery models described above. These results illustrate that white men are

${ }^{12}$ For the backbone process for the refined (2-cored) base-organizational network, because this network was so small we had to increase the alpha level from .05 to .16 (which we found to be the lowest possible alpha value) in order for the model to generate a result.]

${ }^{13}$ Larsen and Ellersgaard (2017) also use an initial step of using betweenness decomposition to reduce 'hangerson' in the network before using this coreness method. We omit this initial step because we want to make our results broadly comparable across different methods. Furthermore, in the case of our analysis of the 2-core network, we don't wish to conduct two methods of initial processing to reduce hangers-on in the network. 14 This is subject to a 'reach' parameter, which we set at 6. Larsen and Ellersgaard set their reach parameter to 2.1, however for our purposes such a low reach threshold can (under some conditions) exclude no one from the core. Our value is also higher because our use of inverted edge weights means that, compared to those individuals with multiple ('weightier') ties to one another, individuals with only single ties to one another are calculated to be more distant, as described above. 
the only group with substantially higher representation in the core than the periphery. White women and almost all non-white groups are rarer in the core than the periphery. There are some notable exceptions, however - for example black women either hold the same level of representation in the core and periphery or else increase their representation in the core, although this varies across methods. In addition, the relative change for white women is very small for the result using the Ma-Mondragon method, but is more evident for the other methods.

Figure 3

Representativeness of Different Groups in Periphery versus Core, Extended Organizational Network
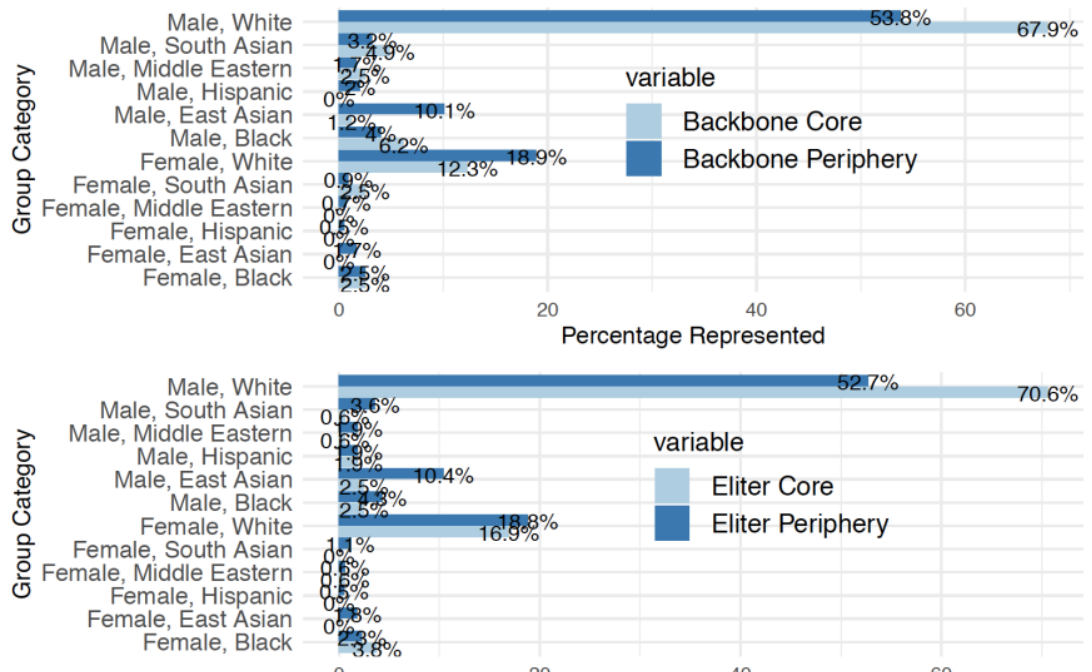

Percentage Represented

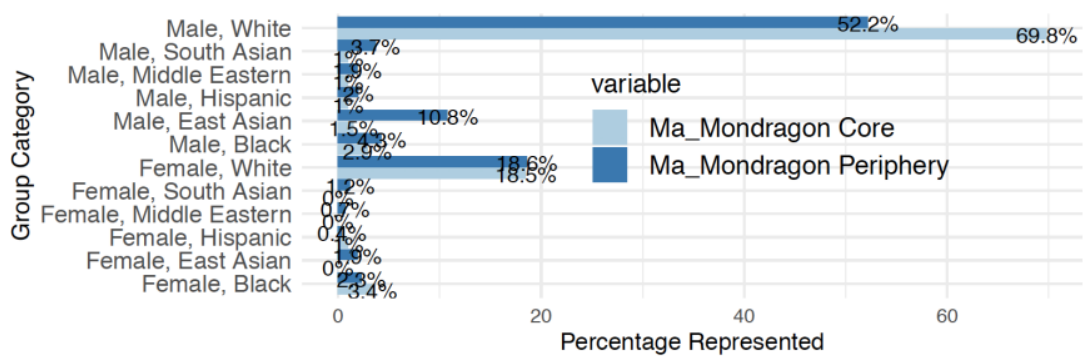

To investigate the consistency of results across methods further, we analyze these data using the same three core-periphery methods but against different kinds of networks in addition to the extended organizational network as described immediately above. The second network we analyze is the much smaller base organizational network, consisting only of the ties between elites arising from board connections to organizations in the global top lists enumerated above. The third kind of network is the 2-core of the extended organizational network - that is, a reduced ('sub-graph') version of the extended organizational network in which only those individuals with 2 or more connections remain, after iteratively culling all those with at least 2 
connections. ${ }^{15}$ Analyzing the core-periphery composition from this network assesses the robustness of our findings against a less inclusive notion of 'elite' - for example in the case that not all organizational leaders are elites, but only those that are more connected (in this case, with a 2-core score and above).

Because of the volume of results - 12 different race-gender categories, across 2 groups (core and periphery), using 3 different methods, with 3 different kinds of networks - we use a graphic depiction of change from the core to the periphery, averaged across the three core-periphery methods to depict our findings. Figure 5 provides a representation of each race-gender category in our data, with men depicted in blue and women in red, with each data point representing the level of level of representation in the periphery versus the core, according to each of the 3 different methods we deploy. The lines running from periphery to core columns are the simple average of the 3 methods in each configuration.

\section{Figure 5}

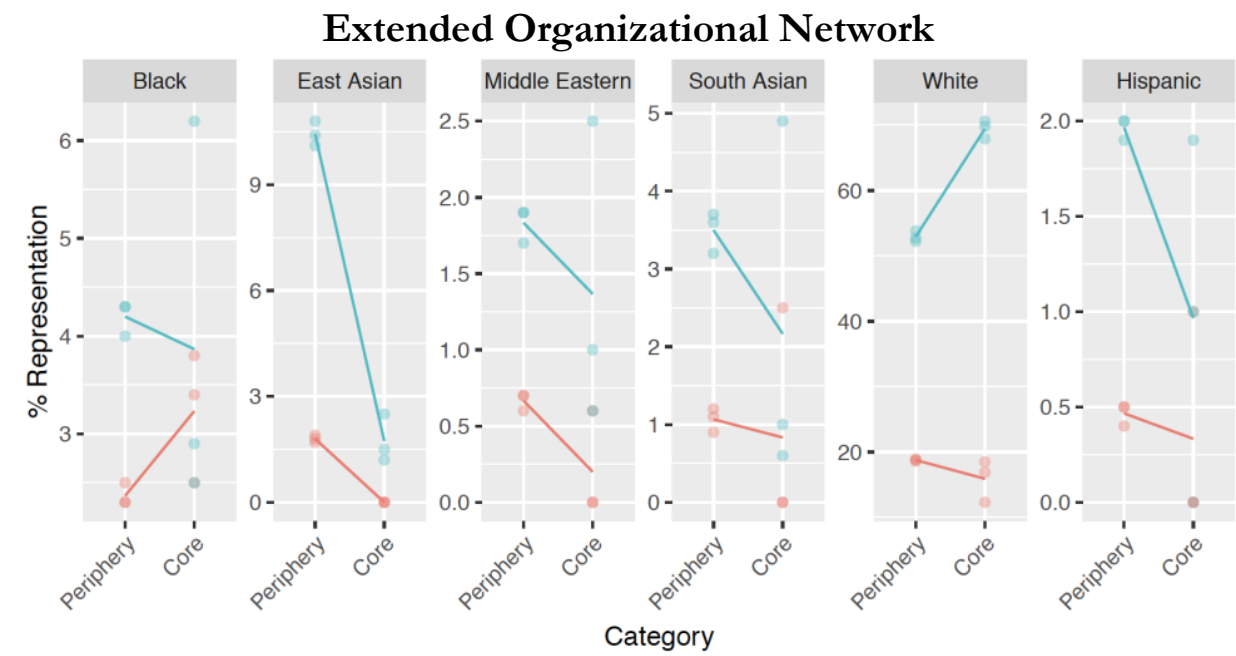

Base Organizational Network

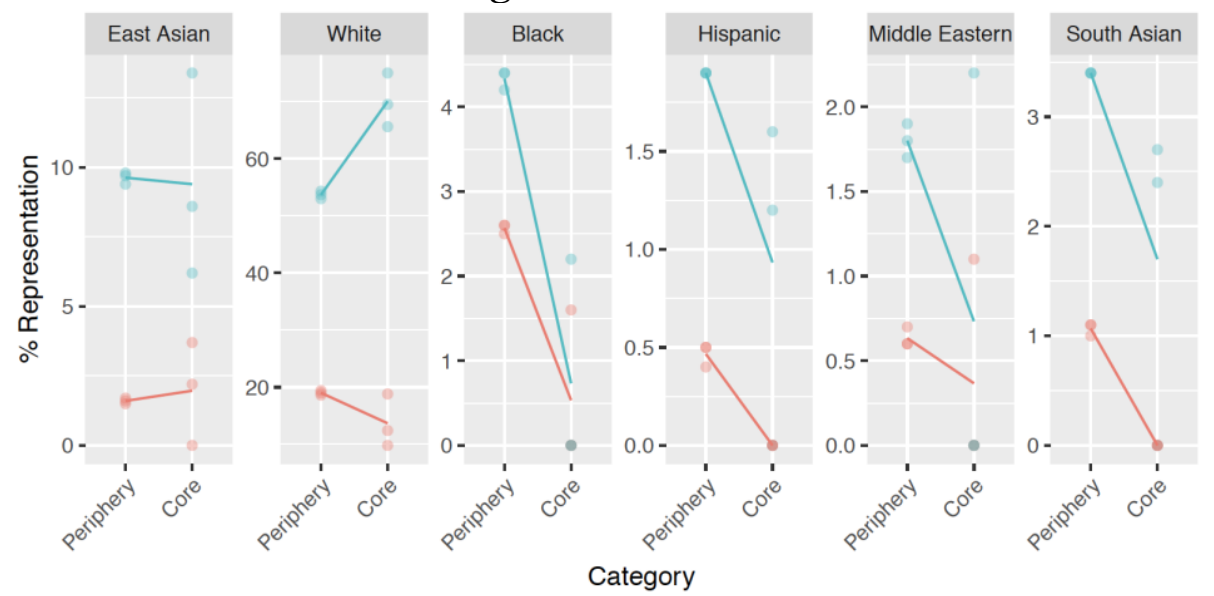

${ }^{15}$ We tried analyzing the 2-core of the base organizational network, but the resultant network of only 32 individuals yields a core of a very small group - in some cases smaller than the number of race and gender categories we have. 


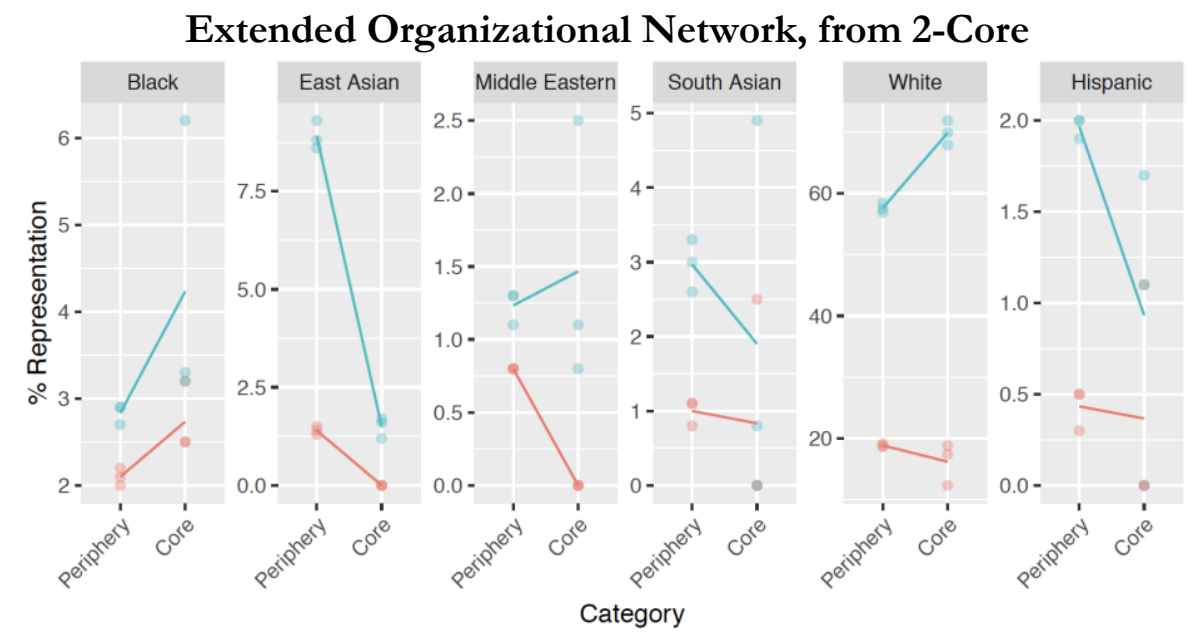

Table 3 provides a summation of our results, across these different networks. We find that for some groups, results are directionally consistent, while for others they are not. For example, for both Hispanic and South Asian men and women, representation declines from the periphery to the core. The same consistent result exists for East Asian women and for White women, which are less well-represented in the core compared to the periphery. The only consistent result which represents an increase in representation is for white men - the only group who are consistently better represented in the core than in the periphery. While some of the inconsistencies in other results may be related to small number of individuals in the sample (e.g. black women), this source of potential error is very unlikely for white men, who are the most abundantly represented group in the entire sample.

Table 3

Summary of Results Across Different Kinds of Networks, with Arrows Depicting Difference in Representation in the Core Compared to the Periphery

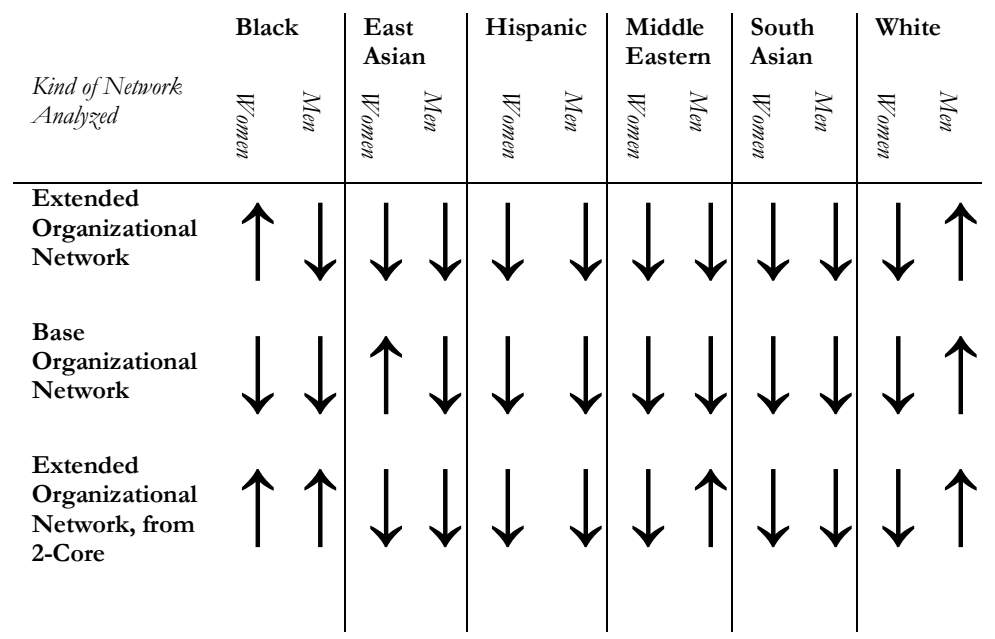

\section{Conclusion}


In this paper we have examined the diversity of global elites, using new data on the board members of a variety of organizations that govern much of global resource allocation, power, policymaking, governance, and public discourse: large corporations, prestigious think tanks, international organizations, NGOs, and transnational policy planning groups. While empirically estimating diversity among elites is not new, previous work has often been confined to corporations or large U.S.-only organizations.

We evaluated the 'core-periphery' hypothesis, predicting that the 'core' of global elite networks have different race and gender representation than the 'periphery'. These are network concepts that relate to longstanding notions of an 'inner circle' of concentrated power within the study of elites and their interrelationships. We found strong and consistent evidence in support of the coreperiphery hypothesis when it came to the largest incumbent group - white men. This was the only group in the categories of race and gender that had a consistently greater proportion of representation in the core compared to the periphery. For many other groups, representation was either inconsistent or consistently declined from the core to the periphery.

While the global elite is dominated by white men, and even more so in the core than the periphery, a full and comprehensive interpretation of this finding is something we leave to further research. A large body of scholarship on racial homophily and on the operation of gender norms in professional life suggests that white men have historically engaged in behavior that marginalized racial minorities and women. Other elite attributes such as age, elite education, and skin tone are also known to act as markers of status within elite circles and may operate alongside race and gender to promote exclusionary dynamics.

Our sample is based on a snapshot of organizations at a single point in time (2018), so an interesting question for future research is how the dynamics we identified may be changing. Numerous board diversity initiatives are under way in many countries, such as Norway and India, and this may have implications for racial and gender representation within global elite networks. So too may the changing geography of wealth, for example among the largest corporations and the wealthiest individuals in the world, which is likely to transform the shape of policy planning boards and international organizations in the years to come.

To our knowledge, this is the only study of racial and gender dynamics within global elite networks across an array of organizations. The diversity of the global elite is relevant to many potential outcomes of interest, from organizational performance to legitimacy to governing behaviour. Moreover, knowledge about how global elites operate is valuable in the context of on-going economic globalization and the changing global distribution of wealth. We have not examined the consequences of elite diversity in this study, or for that matter examined the causal mechanisms that may underlie racial and gender dynamics within these networks. However, this first descriptive step toward understanding the extent and nature of diversity within global elite networks not only reveals the continued marginalization of racial minorities and women in the seats of decisionmaking power but also calls for more analyses of this kind in the future.

\section{References}


Alliance for Board Diversity and Deloitte. 2019. The Missing Pieces Report: The 2018 Board Diversity Census of Women and Minorities on Fortune 500 Boards (New York:: ABD and Deloitte)

Alliance for Board Diversity. 2013. Missing Pieces: Women and Minorities on Fortune 500 Boards 2012 (New York: Alliance for Board Diversity)

Althauser, Robert, Spivack, Sydney and Amsel, Beverly. 1975. The Unequal Elites (New York: John Wiley and Sons).

Baltzell, E. Digby. 1966. Philadelphia Gentlemen: The Making of a National Upper Class (New York: Free Press)

Baltzell, E. Digby. 1987. The Protestant Establishment: Aristocracy and Caste in America (New York: Random House)

Barceló, Joan. 2018. “Are Western-Educated Leaders Less Prone to Initiate Militarized Disputes?” British Journal of Political Science 50(2): 535-566.

Batagelj, Vladimir and Zaversnik, Matjaz. 2002. "An O(m) Algorithm for Cores Decomposition of Networks", Unpublished manuscript.

Bernile, Gennaro, Vineet Bhagwat, and Scott Yonker. 2018. "Board Diversity, Firm Risk, and Corporate Policies." Journal of Financial Economics, 127(3), 588-612.

Bexell, Magdelena. 2014. "Global Governance, Legitimacy and (De)Legitimation", Globalizations 11(3): 289-299.

Bourdieu, P. 1996. The State Nobility: Elite Schools in the Field of Power (Cambridge: Polity Press).

Brown, Terry, Dane, Francis, and Durham, Marcus. 1998. "Perception of Race and Ethnicity", Journal of Social Behavior and Personality 13(2): 295-306.

Cannon, Cecilia. 2013. “Evaluating Non-Governmental Organizations”. IHIED (Graduate Institute), Geneva.

Cardenas, Julian. 2014. “Are Latin America’s Corporate Elites Transnationally Interconnected? A Network Analysis of Interlocking Directorates", Global Networks 15(4): 424-445.

Cárdenas, Julian. 2016. "Why do corporate elites form cohesive networks in some countries, and do not in others? Cross-national analysis of corporate elite networks in Latin America" International Sociology 31(3): 341-363.

Carroll, W. K., Fennema, M., and Heemskerk, E. M., 2010. Constituting Corporate Europe: A Study of Elite Social Organization. Antipode, 42(4), 811-843.

Carroll, William and Carson, Colin. 2003. "Forging a New Hegemony? The Role of Transnational Policy Groups in the Network and Discourses of Global Corporate Governance", Journal of World Systems Research 9(1): 66-102.

Carroll, William and Carson, Colin. 2003. "The Network of Global Corporations and Elite Policy Groups: A Structure for Transnational Capitalist Class Formation? Global Networks 3: 29-57.

Carroll, William and Sapinski, Jean Philippe. 2010. "The Global Corporate Elite and the Transnational Policy-Planning Network, 1996-2006”, International Sociology 25(4): 501-538.

Catalyst. 2017. 2016 Catalyst Census: Women and Men Board Directors Board Seat Analysis (New York: Catalyst)

Chu, Johan and Davis, Gerald. 2016. "Who Killed the Inner Circle? The Decline of the American Corporate Interlock Network", American Journal of Sociology 122(3): 714-754.

Chwieroth, Jeffrey. 2013. "The Silent Revolution: How the Staff Exercise Informal Governance over IMF Lending”, Review of International Organizations 8(2): 265-290.

Cinelli, Matteo, Ferraro, Giovanna, and Iovanella, Antonio. 2017. "Resilience of Core-Periphery Networks in the Case of Rich-Club", Complexity, Article 6548362.

Cohen, J. 1960. "A Coefficient of Agreement for Nominal Scales", Educational and Psychological Measurement 20: 37-46. 
Comet, Catherine. 2017. "How does the Inner Circle Shape the Policy-Planning Network in France", Socio-Economic Review, forthcoming.

Conyon, Martin and Muldoon, Mark. 2006. "The Small World of Corporate Boards", Journal of Business, Finance and Accounting 33(9-10): 1321-1343.

Dabrowski, Marek. 2014. "Center for Social and Economic Research (CASE): Think Tanks in the Era of Globalization”, in James G. McGann, Anna Viden, Jillian Rafferty (Eds), How Think Tanks Shape Social Development Policies (University of Pennsylvania: University of Pennsylvania Press, pp. 213-230.

Davis, G. F., Yoo, M., \& Baker, W. E. 2003. “The Small World of the American Corporate Elite, 1982-2001" Strategic Organization, 1(3): 301-326.

De Graaf, Nana. 2014. "Global Networks and the Two Faces of Chinese National Oil Companies", Perspectives on Global Development and Technology 13(5-6)" 539-563.

De Graaf, Nana. 2019. "China Inc Goes Global: Transnational and National Networks of China's Globalizing Business Elite", Review of International Political Economy 27(2): 208-233.

De Graaff, Naná and Van Apeldoorn, Bastiaan. 2017. 'US Elite Power and the Rise of 'Statist' Chinese Elites in Global Markets", International Politics 54(3): 338-355.

De Graaff, Naná and Van Apeldoorn, Bastiaan. 2018. "US-China relations and the liberal world order: contending elites, colliding visions?", International Affairs 94(1): 113-131.

Deloitte. 2017. Missing Pieces Report: The 2016 Board Diversity Census of Women and Minorities on Fortune 500 Boards (Alliance for Board Diversity)

Dietz, Thomas, Dotzauer, Marius and Cohen, Edward. 2019. "The Legitimacy Crisis of Investor-State Arbitrarion and the New EU Investment Court System”, Review of International Political Economy_26(4): 749-772.

Domhoff, G. William and Zweigenhaft, Richard L. 2011. The New CEOs: Women, African American, Latino and Asian American Leaders of Fortune 500 Companies (Lanham: Rowman and Littlefield)

Ellersgaard, Christoph Houman, Larsen, Anton Grau and Munk, Martin D. 2013. "A Very Economic Elite: The Case of the Danish Top CEOs”, Sociology 47(6): 1051-1071.

Fennema, Meindert and Heemskerk, Eelke. 2018. "When Theory Meets Methods: The Naissance of Computer Assisted Corporate Interlock Research”, Global Networks 18: 81104.

Fernandez, R. M., \& Fernandez-Mateo, I. 2006. "Networks, Race, and Hiring" American Sociological Review 71(1): 42-71.

Fraussen, Bert and Halpin, Darren. 2017. "Think Tanks and Strategic Policy-Making: the Contribution of Think Tanks to Policy Advisory Systems”, Policy Sciences 50(1): 105-124.

Fuhrmann, Matthew, and Michael C. Horowitz. 2014. "When leaders matter: Rebel experience and nuclear proliferation" Journal of Politics 77(1): 72-87.

Garsten, Christina. 2014. "All About Ties: Think Tanks and the Economy of Connections", in Christina Garsten and Anette Nyqvist (Eds), Organisational Anthropology: Doing Ethnography in and Among Complex Organisation (London: Pluto Press).

Gift, Thomas, and Daniel Krcmaric. 2017. "Who Democratizes? Western-educated leaders and regime transitions", Journal of Conflict Resolution 61(3): 671-701.

Gwet, K. 2008. "Computing Inter-Rater Reliability and its Variance in the Presence of High Agreement", British Journal of Mathematical and Statistical Psychology 61: 29-48.

Hagendorff, Jens and Keasey, Kevin. 2012. "The Value of Board Diversity in Banking: Evidence from the Market for Corporate Control”, European Joumal of Finance 18(1): 41-58.

Hale, Thomas, Held, David and Young, Kevin. Gridlock: Why Global Cooperation is Failing When it is Needed Most (Cambridge: Polity Press) 2013 
Heemskerk, Eelke and Fennema, Meindert. 2014. "Women on Board: Female Board Membership as a Form of Elite Democratization", Enterprise and Society 15(2): 252-284

Heemskerk, Eelke and Takes, Frank. 2016. "The Corporate Elite Community Structure of Global Capitalism”, New Political Economy 21(1): 90-118.

Heemskerk, Eelke, Young, Kevin, Takes, Frank, Cronin, Bruce, Garcia-Bernardo, Javier Popov, Vladimir, Winecoff, W. Kindred, Henriksen Lasse Folke and Laurin-Lamonthe, Audrey. 2018. "Big Corporate Network Data: Problems, Diagnostics and Fixes", Global Networks 18(1): 3-32.

Heerwig, Jennifer, and Murray, Joshua. 2018. "The Political Strategies and Unity of the American Corporate Inner Circle: Evidence from Political Donations, 1982-2000”, Social Problems 66(4): 580-608.

Held, D. and K. Young. 2013. 'Global Governance in Crisis? Fragmentation, Risk and World Order'. International Politics 50(3), 309-332.

Horowitz, Michael C., and Allan C. Stam. 2014. "How prior military experience influences the future militarized behavior of leaders" International Organization 68(3): 527-559.

Kentikelenis, Alexander and Seabrooke, Leonard. 2017. "The Politics of World Polity: Scriptwriting in International Organizations” American Sociological Review, 82(5), 1065-1092

Khan, Shamus Rahman. 2012. "The Sociology of Elites", Annual Review of Sociology, 38: 361-377.

Kojaku, Sadamori and Masuda, Naoki. 2018. "Core-Periphery Structure Requires Something Else in the Network", New Journal of Physics 20, Article 043012.

Larsen, Anton Grau and Ellersgaard, Christoph Houman. 2017. "Identifying Power Elites: KCores in Heterogenous Affiliation Networks", Social Networks 50(7): 55-69.

Larsen, Anton Grau and Ellersgaard, Christoph. 2018. "The Inner Circle Revisited: The Case of a Negotiated Economy”, Socio-Economic Review 16(2): 251-275.

Li, Haishan and Chen, Peng. 2018. "Board gender diversity and firm performance: The moderating role of firm size" Business Ethics: A European Review 27(4): 294-308.

Luna, Matilde and Valasco, Jose. 2017. "Power Without Representation: the Coherence and Closeness of the Trilateral Commission", in Salas-Porras, Alejandra and Murray, Georgina (Eds), Think. Tanks and Global Politics: Key Spaces in the Structure of Power (New York: Springer), pp. 81-106.

Luther-Davies, Philip, Doniec, Kasia Julia, Lavalee, Joseph, Domhoff, G. William, and King, Lawrence. 2020. "Corporate Political Power and US Foreign Policy, 1981-2002: The Role of the Policy Planning Network", Political Economy Research Institute (PERI) Working Paper.

Ma, A and Mondragón, RJ. 2015. "Rich-Cores in Networks", PLoS ONE 10(3): 1-13.

Mareva Sabatier. 2015. "A women's boom in the boardroom: effects on performance?”, Applied Economics, 47:26, 2717-2727

Marple, Tim, Bruce Desmarais, and Kevin L. Young. 2017. “Collapsing corporate confusion: Leveraging network structures for effective entity resolution in relational corporate data" 2017 IEEE International Conference on Big Data (Big Data). IEEE.

Marple, Tim. 2020. "The social management of complex uncertainty: Central Bank similarity and crisis liquidity swaps at the Federal Reserve" Review of International Organizations, forthcoming.

Martin, C. José García and Herrero, Begoña. 2018. "Boards of Directors: Composition and Effects on the Performance of the Firm", Economic Research 31(1): 1015-1041.

Mayer, Roger, Warr, Richard and Zhao, Jing. 2018. "Do Pro-Diversity Policies Improve Corporate Innovation?” Financial Management, 47(3), 617-650

McGann, James. 2016. "The Revolving Door" in The Fifth Estate: Think Tanks, Public Policy, and Governance”, (Washington, D.C.: Brookings Institution Press), pp. 62-78. 
McGann, James. 2018. Global Go To Think Tank Index Report (Philadelphia: Foreign Policy Research Institute)

McGann, James. Viden, A., \& Rafferty, J. (Eds.). (2014). How Think Tanks Shape Social Development Policies (Philadelphia: University of Pennsylvania Press)

Mills, C.Wright. 1956. The Power Elite (Oxford: Oxford University Press)

Misztal, B. 2012. "Public Intellectuals and Think Tanks: A Free Market in Ideas?", International Journal of Politics, Culture, and Society, 25(4): 127-141.

Mizruchi, Mark. 2013. The Fracturing of the American Corporate Elite (Cambridge: Harvard University Press)

Murray, Georgina. 2001. "Black Empowerment in South Africa - a Corporate Black Wash”, Critical Sociology, 26(3): 183-204.

Murray, Georgina. 2006. Capitalist Networks and Social Power in Australia and New Zealand (New York: Ashgate)

Murray, Joshua. 2014. "Evidence of a transnational capitalist class-for-itself: the determinants of PAC activity among foreign firms in the Global Fortune 500, 2000-2006" Global Networks, 14: 230-250.

Murray, Joshua. 2017. "Interlock Globally, Act Domestically: Corporate Political Unity in the $21^{\text {st }}$ Century", American Journal of Sociology 122(6): 1617-1663.

Naudet, Jules and Dubost, Claire-Lise. 2017. "The Indian exception: the densification of the network of corporate interlocks and the specificities of the Indian business system (2000-2012)", Socio-Economic Review, 15(2): 405-434.

Nelson, Stephen. 2014. "Playing Favorites: How Shared Beliefs Shape the IMF's Lending Decisions.” International Organization 68(2): 297-328

Quah, Danny. 2011. “The Global Economy's Shifting Centre of Gravity” Global Policy, 2: 3-9

Rich, Andrew. 2004. Think Tanks, Public Policy, and the Politics of Expertise (Cambridge: Cambridge University Press)

Richard, Orlando, Kirby, Susan and Chadwick, Ken. 2013. "The impact of racial and gender diversity in management on financial performance: How participative strategy making features can unleash a diversity advantage", International Journal of Human Resource Management 24(13): 2571-2582.

Rombach, Puck, Porter, Mason, Fowler, James and Mucha, Peter. 2017. "Core-Periphery Structure in Networks (Revisited)", Society for Industrial and Applied Mathematics 74(1): 167190.

Roth, Wendy. 2016. “The Multiple Dimensions of Race”, Ethnic and Racial Studies 39(8): 13101338.

Roth, Wendy. 2017. "Methodological Pitfalls of Measuring Race: International Comparisons and Repurposing of Statistical Categories", Ethnic and Racial Studies 40(13): 2347-2353.

Royster, Deirdre A. 2003. Race and the Invisible Hand: How White Networks Exclude Black Men from Blue-Collar Jobs (Los Angeles: University of California Press)

Salas-Porras, Alejandra and Murray, Georgina. 2017. Think Tanks and Global Politics: Key Spaces in the Structure of Power (New York: Springer)

Sapinsky, Jean-Philippe. 2015. "Constructing Climate Capitalism: Corporate Power and the Global Climate Policy-Planning Network”, Global Networks 16(1): 89-111.

Scherer, N. and Curry, B. 2010. "Does Descriptive Race Representation Enhance Institutional Legitimacy? The Case of the U.S. Courts" Journal of Politics 72(1): 90-104.

Schoettli, Jivanta and Pohlmann, Markus. 2017. "A New Economic Elite in India: Transnational and Neoliberal?", South Asia Multidisciplinary Academic Journal 15.

Scott, John. 1985. In Frans Stokman, Rolf Ziegler and John Scott (Eds), Networks of Corporate Power: A Comparative Analysis of Ten Countries (Cambridge: Polity Press) 
Scott, John. 1991. "Networks of Corporate Power: A Comparative Assessment", Annual Review of Sociology 17(1): 181-203.

Seabrooke, L. and E.R. Nilsson. 2015. 'Professional Skills in International Financial Surveillance: Assessing Change in IMF Policy Teams', Governance 28(2): 237-254.

Seabrooke, Leonard and Henriksen, Lasse (Eds.). 2017. Professional Networks in Transnational Governance (Cambridge: Cambridge University Press).

Seabrooke, Leonard and Tsingou, Eleni. 2014. "Distinctions, Affiliations, and Professional Knowledge in Financial Reform Expert Groups", Journal of European Public Policy, 21(3): 389-407.

Seidman, S. B. 1983. "Network Structure and Minimum Degree", Social Networks 5: 269-287.

Serrano, M. Angeles, Boguna, Marian, and Vespignani, Allessandro. 2009. "Extracting the Multiscale Backbone of Complex Weighted Networks", PNAS 106(16): 6483-6488.

Shoup, Lawrence. 2015. Wall Street's Think Tank: The Council on Foreign Relations and the Empire of Neoliberal Geopolitics, 1976-2014 (New York: NYU Press).

Simon, Patrick and Piche, Victor. 2012. "Accounting for Ethnic and Racial Diversity: The Challenge of Enumeration”, Ethnic and Racial Studies 35(8): 1357-1365.

Sklar, Holly (Ed). 1980. Trilateralism: The Trilateral Commission and Elite Planning for World Management (Boston: South End Press)

Soares, Rachel, Foust-Cummings, Heather, Fancoeur, Claude and Labelle, Réal. 2015. Companies Behaving Responsibly: Gender Diversity on Boards (New York: Catalyst).

Stokman, Frans, Ziegler, Rolf and Scott, John. 1985. Networks of Corporate Power: A Comparative Analysis of Ten Countries (Cambridge: Polity)

Struyk, Raymond. 2002. Management of Transnational Think Tank Networks. International Journal of Politics, Culture, and Society 15(4), 625-638.

Thomas, James. 2020. Diversity Regimes: Why Talk is Not Enough to Fix Racial Inequality at Universities (New Brunswick: Rutgers University Press).

Tsingou, Eleni. 2015. "Club Governance and the Making of Global Financial Rules", Review of International Political Economy 22(2): 225-256.

Useem, Michael. (1984). The Inner Circle: Large Corporations and the Rise of Business Political Activity in the U.S. and U.K. (Oxford: Oxford University Press)

Vion, Antoine, Doudouet, Francois-Xavier and Gremont, Eric. 2015. "The Euro Zone Corporate Elite at the Cliff Edge (2005-2008): A New Approach of Transnational Interlocking", Elites on Trial (Research in the Study of Organizations, Emerald Insight), pp. 165-187.

Warikoo, Natasha. 2016. The Diversity Bargain (Chicago: University of Chicago Press)

Wile, Rob. 2012. "MAP: The World's Economic Center of Gravity from AD1 to AD 2010", Business Insider, 29 June. Available at: https://www.businessinsider.com/mckinseyworlds-economic-center-of-gravity-2012-6

Wu, Jie, Richard, Orlando C., Zhang, Xinhe and Macaulay, Craig. 2019. “Top Management Team Surface-Level Diversity, Strategic Change, and Long-Term Firm Performance: A Mediated Model Investigation" Journal of Leadership and Organizational Studies 26(3): 304318.

Young, Kevin, Marple, Tim and Heilman, James. 2017. "Beyond the Revolving Door: Advocacy Behavior and Social Distance to Financial Regulators", Business and Politics 19(2): 327-364.

Young, Kevin. 2015. "Not By Structure Alone: Power, Prominence and Agency in American Finance", Business and Politics 17(3): 443-472.

Zieliński, Aleksander. 2017. "The Bilderberg Conferences: A Transnational Informal Governance Network" in Salas-Porras, Alejandra and Murray, Georgina (Eds), Think Tanks and Global Politics: Key Spaces in the Structure of Power (New York: Springer), pp. 107132. 
Zuern, Michael. 2018. A Theory of Global Governance: Authority, Legitimacy, and Contestation (Oxford: Oxford University Press)

Zweigenhaft, Richard L. and Domhoff, G. William. 2003. Blacks in the White Elite: Will the Progress Continue? (Lanham: Rowman and Littlefield).

Zweigenhaft, Richard L. and Domhoff, G. William. 2006. Diversity in the Power Elite: How it Happened, Why it Matters (Lanham: Rowman and Littlefield).

Zweigenhaft, Richard L. and Domhoff, G. William. 2018. Diversity in the Power Elite: Ironies and Unfulfilled Promises (Lanham: Rowman and Littlefield).

Zweigenhaft, Richard L. and Riplinger, Kyle. 2011. "Baby-Faced and More: CEOs and Skin Color" in The New CEOs: Women, African American, Latino and Asian American Leaders of Fortune 500 Companies (Lanham: Rowman and Littlefield), pp. 159-170.

Zweigenhaft, Richard. 1982. Jews in the Protestant Establishment (New York: Praeger)

Zweigenhaft, Richard. 2003. Blacks in the White Elite: Will the Progress Continue (Oxford: Rowman and Littlefield) 